\title{
RESULT STUDY OF DESTINATION AND SATISFACTION OF CHINESE TOURISTS, VISITING MONGOLIA
}

\author{
Urnult B., Geography department of the School of Mathematics and Nature Science, Mongolian \\ National University of Education (MNUE), \\ International University in Erlian branch of Inner Mongolian Teacher's University \\ Badam Ariya, Master of Geography Science, Division of Land use and Land resource research, The \\ Institute of Geography and Geoecology, MAS (IGG), Ulaanbaatar, Mongolia \\ Tsogbadral Khurelbaatar, Doctor (Ph.D) of Geography, Department of Geography, Mongolian \\ National University of Education (MNUE), Ulaanbaatar, Mongolia
}

\section{DOI: https://doi.org/10.31435/rsglobal_conf/30112020/7268}

\begin{abstract}
With the increasing number of foreign tourists visiting Mongolia, new tourist products and regional destinations are emerging. In recent years, the number of foreign tourists visiting Mongolia has increased, with Chinese tourists accounting for one-third of the market, and this growth is expected to continue. Thus, the results of a sample survey of 750 tourists and residents of Chinese tour operators in Mongolia have compiled 74 (18 groups) indicators reflecting the direction and satisfaction of Chinese tourists visiting Mongolia.

The results of the study identified 9 regions where Chinese tourists are more inclined to travel to Mongolia and summarized 9 factors that are necessary to improve Destination management.

The results of the study were ranked according to the Gray method, and the satisfaction score was assessed by quantitative and qualitative methods. As a result of this assessment, this paper shows that Ulaanbaatar, Gorkhi-Terelj National Park, and border regions are more satisfied.
\end{abstract}

Keywords: Destination, competitiveness, Tourists'satisfaction, Destination ranking, Gray method.

Introduction. One of the main vital concepts of tourism is the comprehension of a tourist destination. As described in the tourism study, "Destination" is a place to visit for tourism purposes. The tourist destination was described as follows by author Clare A. Gunn ${ }^{1}$. "A tourist destination" is a place that provides visitors with services and exhibits to enjoy their leisure time", he described. According to this view, tourist destination must include tourist attractions, products, and services that may be required during travel, and infrastructure to ensure the safety and comfort of the tourists.

Determining the competitiveness of a destination is an important part of tourism competitiveness, and calculation attempts have begun in the 1990s. Researchers believe that destinations will be existent in competition and lead through implementing environmental management, providing participation in public-private partnerships, and improving position in the market $^{1}$. Competitiveness of a tourist destination ${ }^{2}$ is considered to be a strong and efficient permanent position in the market. The main ways to promote competitiveness are to increase the tourism revenue and the number of tourists in the destination and to introduce and apply new products and services based on the results of the satisfaction survey.

Research purpose. The purpose of this study is to investigate and rank competitiveness and destination resources by reviewing the satisfaction and current situation of Chinese tourists, visiting Mongolia. This will create the basic conditions for updating and increasing the number of travel products and services offered to Chinese tourists under the demand of tourists.

Research methodology. This study is about influence factors on the satisfaction of Chinese tourists, visiting Mongolia, and utilized a rank order survey. Analysis on current situation and satisfaction on Chinese tourists, visiting Mongolia has been made. The survey was developed by random sample of Chinese tourists visiting Mongolia in 2018 - 2019 (a total of 750), 8 groups and 33 indicators of "Factors influencing tourist satisfaction" research model of authors (Li Tian Yuan, 2012),

\footnotetext{
${ }^{1}$ Beneditti J. "The competitiveness of Brazil as Dutch holiday destination”. 2010

${ }^{2}$ Baatartsooj G. "Stable tourism" UB city, 2006
} 
1 group and 4 indicators of Mongolia's main tourist regions and destinations, a total of 9 groups and 37 indicators, and the level of satisfaction of factor is evaluated in 5 steps. The order of factors was determined by the Gray correlation method.

In modern times, the Gray correlation method is widely used to determine rankings. Gray correlation analysis is aimed at determining hierarchies using simple calculations rather than specific statistical distributions, and is generally similar to the World Economic Forum's Competitiveness Index methodology, but is an effective and flexible method used in the multidisciplinary analysis. The advantage of the Gray system is that it can analyze both specific issues and incomplete information. This is an analytical tool, especially in the absence of information. This was proposed by Deng Ju long, a scientist at the Huazhong University of Science and Technology in China, in line with the Gray system theory.

Gray correlation analysis is based on a method of measuring the relationship between factors. Gray correlation is a method aimed at determining the order of things by simple calculations without the need for small amounts of information and specific statistical distributions. Gray correlation analysis consists of 5 basic steps.

Step1. Find the maximum value and the minimum value in the basic order

Step 2. Determine the relationship

a. High to low: Indication to show a list of the distance from China to the destination from high to low.

$$
x_{i}^{*}(k)=\frac{x_{i}^{(o)}(k)-\min \left\{x_{i}^{(0)}(k)\right\}}{\max \left\{x_{i}^{(0)}(k)\right\}-\min \left\{x_{i}^{(0)}(k)\right\}}
$$

$i-$ factor

$k-$ satisfaction level

$x_{i}^{(o)}-$ normal coefficient or basic order

$x_{i}^{*}(k)$ - comparison sequence, $i$ factor ба $(k)$

satisfaction level

b. Low to high: Indication to show a list of the distance from China to the destination from low to high.

$$
x_{i}^{*}(k)=\frac{\max \left\{x_{i}^{(0)}(k)\right\}-x_{i}^{(0)}(k)}{\max \left\{x_{i}^{(0)}(k)\right\}-\min \left\{x_{i}^{(0)}(k)\right\}}
$$

Then find the maximum value of the above coefficient and the maximum value is equal to 1 .

Step3. Calculate the absolute value between $x_{0}^{*}(k)$ ба $x_{0}^{* i}(k): \Delta_{o i}(k)=x_{0}^{*}(k)-x_{i}^{*}(k)$

In other words, subtract each value of the comparison sequence from the maximum value of the comparison sequence.

Step4. Find correlation. $x_{0} \in X_{0}$ Main sequence and $x_{0 i} \in X_{i}$ comparison sequences are sets of $\mathrm{X}$ factor. Also, it will represent the correlation of $x_{0}(k), x_{i}(k)$.

$$
r_{k}^{0}\left(x_{0}(k), x_{i}(k)\right)=\frac{\min _{i} \min _{k}\left\{x_{o}(k)-x_{i}(k)\right\}+\zeta \max _{i} \max _{k}\left\{x_{o}(k) x_{i}(k)\right\}}{x_{o}(k) x_{i}(k) \zeta \max _{i} \max _{k}\left\{x_{o}(k)-x_{i}(k)\right\}}
$$

$\zeta$ (sort factor) is belong to $\in[0, \infty]$, however, have value between $[0 ; 1] . \zeta$ is high in sort when the number is low, and generally, it should be less than 0.5.

$$
\begin{aligned}
& \Delta_{\min }=\Delta_{o j}(k)=\left\{x_{o}-x_{k}\right\} \\
& \Delta_{\text {max }}=\Delta_{o j}(k)=\left\{x_{o}-x_{k}\right\}
\end{aligned}
$$

The main function of the sort factor $\zeta$ is to adjust the relationship between the base value and the measured value and the measured value.

Step5. Find the correlation order.

The degree of Gray correlation is calculated by the following formula.

$$
r_{k}^{0}\left(x_{i}, x_{i}\right)=\frac{1}{n_{k}} \sum_{k=1}^{n} r\left(x_{i}(k), x_{i}(k)\right)
$$

$r_{k}^{0}\left(x_{i}, x_{i}\right)$ Factor, the aggregate index of $\mathrm{k}$ of $(0), \mathrm{n}_{\mathrm{k}}$ is the number of variables in $\mathrm{k}$ indicator.

Result and discussion. A total of 750 subjects were chosen randomly and questioned according to the question below (Table 1). 
Table. 1. General information (frequency, percent)

\begin{tabular}{|c|c|c|c|}
\hline \multicolumn{2}{|l|}{ Basic information } & \multirow{2}{*}{$\begin{array}{c}\text { Frequency } \\
347\end{array}$} & \multirow{2}{*}{$\begin{array}{c}\text { Percent } \\
46.3\end{array}$} \\
\hline & Male & & \\
\hline Gender & Female & 403 & 53.7 \\
\hline \multirow{6}{*}{ Age } & Under 20 & 6 & 0.8 \\
\hline & $21-30$ & 108 & 14.4 \\
\hline & $31-40$ & 198 & 26.4 \\
\hline & $41-50$ & 217 & 28.9 \\
\hline & $51-60$ & 133 & 17.7 \\
\hline & Below 60 & 88 & 11.7 \\
\hline \multirow{7}{*}{ Job } & Student & 11 & 1.5 \\
\hline & Self-employed & 139 & 18.5 \\
\hline & Retired & 91 & 12.1 \\
\hline & Worker & 21 & 2.8 \\
\hline & Farmer, herder & 95 & 12.7 \\
\hline & Entrepreneur & 79 & 10.5 \\
\hline & Civil servant & 314 & 41.9 \\
\hline \multirow{5}{*}{ Level of Education } & Secondary school & 70 & 9.3 \\
\hline & High and vocational school & 89 & 11.9 \\
\hline & College & 151 & 20.1 \\
\hline & Graduate degree & 345 & 46.0 \\
\hline & Postgraduate degree & 95 & 12.7 \\
\hline \multirow{7}{*}{ Income (month) } & Under 2000 yuan & 29 & 3.9 \\
\hline & 2001-4000 yuan & 157 & 20.9 \\
\hline & $4001-6000$ & 187 & 24.9 \\
\hline & $6001-8000$ & 164 & 21.9 \\
\hline & $8001-10000$ & 122 & 16.3 \\
\hline & $10001-20000$ & 72 & 9.6 \\
\hline & Below 20001 yuan & 19 & 2.5 \\
\hline \multirow{3}{*}{ Frequency of travel } & Once & 401 & 53.5 \\
\hline & Twice & 245 & 32.7 \\
\hline & more than 3 & 104 & 13.9 \\
\hline \multirow{4}{*}{ Duration of travel } & Under 2 & 10 & 1.3 \\
\hline & 3-4days & 130 & 17.3 \\
\hline & 5-6days & 248 & 33.1 \\
\hline & More than 7 days & 362 & 48.3 \\
\hline \multirow{6}{*}{ The total expense of travel } & Under 3000 & 79 & 10.5 \\
\hline & $3001-5000$ & 244 & 32.5 \\
\hline & $5001-8000$ & 195 & 26.0 \\
\hline & $8001-10000$ & 142 & 18.9 \\
\hline & $10001-15000$ & 67 & 8.9 \\
\hline & $\begin{array}{l}\text { Below } 15000 \\
\end{array}$ & 23 & 3.1 \\
\hline
\end{tabular}

A sample profile indicates that $53,7 \%$ were females while $46,3 \%$ were males. According to age, $26,4 \%$ is between the ages of $31-40,28,9 \%$ is between the ages of $41-50$, which is the majority. Whereas only $0,8 \%$ is aged under 20 , the lowest in the area. Findings indicate that the civil servants are relatively high possibility to travel with $41,9 \%$, yet students and workers are in the opposite. In terms of education level, 58.7 percent of the participants had a post-graduate education or higher education, and 67.7 percent of the participants had a monthly income of 2001-8000 yuan.

In the frequency of travel, 53.5 percent are first-time tourists to Mongolia, and the percentage of tourists who travel for 5-6 days or more than 7 days is high, which is 81.4 percent, and the total cost per tourist is around 3001-10,000 yuan, which is the total of 77.5 percent participants.

According to the frequency of participants destinations (Figure 1), the highest number of participants was in the Ulaanbaatar region (720), and 675 was in the Gorkhi-Terelj National Park, 330 
was in the Orkhon Valley, 36.9 percent was in the Khuvsgul region, and 32 percent was in the Eastern region, 9.1 percent was in Bulgan-Selenge region, 6 percent was in Gobi region, 35 percent was High Mountain region, and 4.3 percent was in the border region.

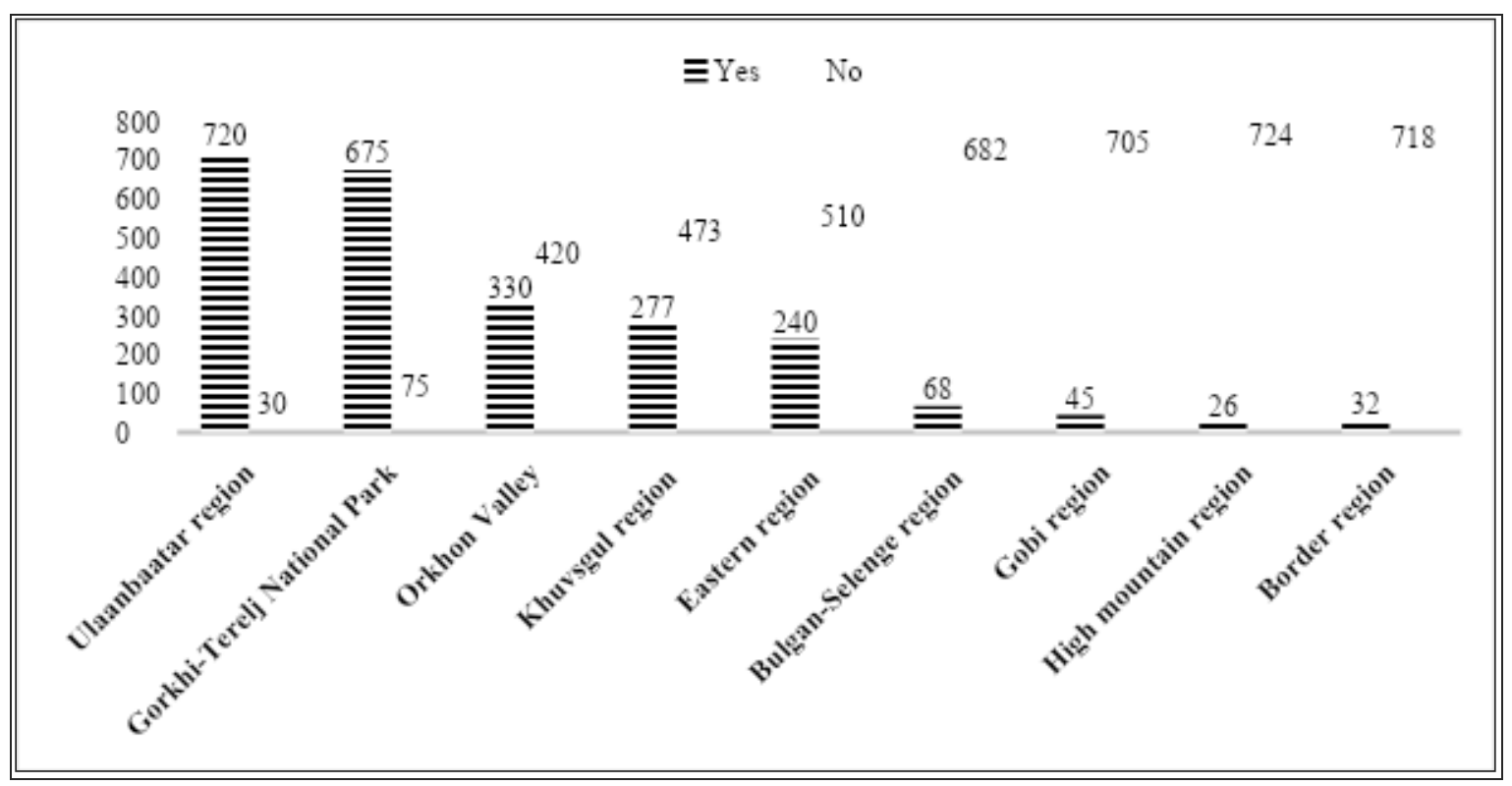

Fig. 1 Frequency and region of destination

The followings are indicators of factors influencing satisfaction. (Table 2)

Table 2. Factors influencing satisfaction

\begin{tabular}{|l|l|l|}
\hline № & \multicolumn{1}{|c|}{ Factor } & \multicolumn{1}{c|}{ Satisfaction } \\
\hline 1 & Satisfaction with nature & $\begin{array}{l}\text { The value, types, characteristics of nature, cost of a } \\
\text { ticket }\end{array}$ \\
\hline 2 & $\begin{array}{l}\text { Satisfaction with travel environment, } \\
\text { weather, and atmosphere }\end{array}$ & $\begin{array}{l}\text { Urban-rural style, clean environment, pleasant } \\
\text { atmosphere, and social safety }\end{array}$ \\
\hline 3 & Satisfaction with accommodation & Accommodation price, comfort, and quality \\
\hline 4 & Satisfaction with food service & A specialty of food, price, hygiene \\
\hline 5 & Satisfaction with souvenir & Rural areas souvenirs, price, choices, market demand \\
\hline 6 & Event & $\begin{array}{l}\text { Features, types, prices, and quality of anniversary } \\
\text { events }\end{array}$ \\
\hline 7 & Satisfaction with transportation & Transportation, types, communication, high road \\
\hline 8 & Satisfaction with travel service & $\begin{array}{l}\text { Guide skills, local friendliness, integrated travel } \\
\text { information system, signage }\end{array}$ \\
\hline 9 & Destination & $\begin{array}{l}\text { Destination selection, historical and cultural exhibits, } \\
\text { accessibility, and personal assessment of the } \\
\text { destination }\end{array}$ \\
\hline
\end{tabular}

Participants rated 1-5 on each of the 37 indicators of 9 groups of the study ("excellent-5, good4 , medium-3, bad-2, very bad-1"). Rates were collected, analyzed and the average was calculated using the SPSS program:

"EXCELLENT"

combined with "excellent + good rating";

"Medium" rating is "PLEASANT"

"UNPLEASANT"

Combined with "bad + very bad"

Based on the number of participants considered the most favorable, Gray calculated the ranking of the factors using the correlation method.

Factors influencing tourist satisfaction (frequency) and "Destination" ranking

Rates were summarized using the "SPSS" program and the average was made as "excellent + good rating"="EXCELLENT", "Medium" ="PLEASANT", and "bad + very bad" ="UNPLEASANT". 
The rankings of each indicator (Table 3) were converted to scores, and the scores were aggregated to produce a general ranking.

General Ranking (Table 3) has been made as calculating the overall point of each destination based on the transfer of each satisfaction indicator, such as 9 points for Rank I, 8 points for Rank II, 7 points for Rank III, and so on.

Table 3. Competitiveness ranking (Gray Method)

\begin{tabular}{|c|c|c|c|c|c|c|c|c|c|c|c|c|c|c|c|c|c|c|c|c|c|}
\hline \multirow[t]{2}{*}{ № } & \multirow{2}{*}{ 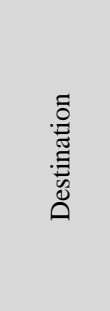 } & \multicolumn{2}{|c|}{ 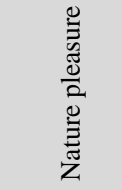 } & \multicolumn{2}{|c|}{ 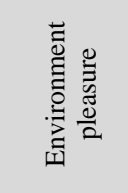 } & \multicolumn{2}{|c|}{ 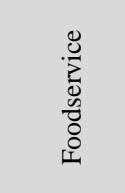 } & \multicolumn{2}{|c|}{ 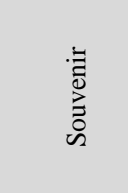 } & \multicolumn{2}{|c|}{ 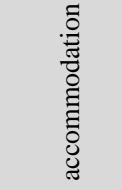 } & \multicolumn{2}{|c|}{ 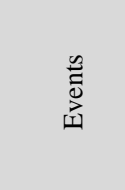 } & \multicolumn{2}{|c|}{ 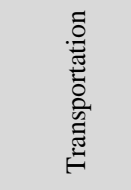 } & \multicolumn{2}{|c|}{ 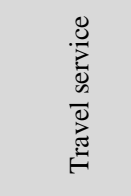 } & \multicolumn{2}{|c|}{ 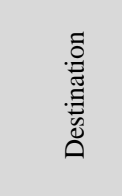 } & \multicolumn{2}{|c|}{ 䒿 } \\
\hline & & 兰 & ڤั & 兰 & : & 䒕 & 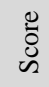 & 壬 & ̋ँ & 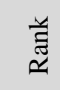 & 苛 & 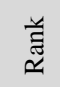 & $\begin{array}{l}0 \\
\check{0} \\
\mathscr{n}\end{array}$ & 苨 & $\begin{array}{l}0 \\
\text { ¿ } \\
\ddot{n}\end{array}$ & 苨 & $\begin{array}{l}0 \\
\vdots \\
\tilde{U}\end{array}$ & 范 & 苛 & 華 & $\begin{array}{l}0 \\
\tilde{0} \\
\mathscr{n}\end{array}$ \\
\hline 1 & $\begin{array}{l}\text { Ulaan- } \\
\text { baatar }\end{array}$ & IY & 6 & II & 8 & YI & 4 & IY & 6 & IY & 6 & IY & 6 & YI & 4 & IY & 6 & IY & 6 & II & 52 \\
\hline 2 & \begin{tabular}{|c|} 
Gorkhi- \\
Terelj \\
\end{tabular} & III & 7 & YI & 4 & $\mathrm{Y}$ & 5 & III & 7 & $\mathrm{Y}$ & 5 & $\mathrm{Y}$ & 5 & IY & 6 & IX & 1 & YII & 3 & YI & 43 \\
\hline 3 & \begin{tabular}{|c|}
$\begin{array}{c}\text { Orkhon } \\
\text { valley }\end{array}$ \\
\end{tabular} & Y & 5 & YII & 3 & IY & 6 & II & 8 & YI & 4 & II & 8 & II & 8 & YI & 4 & III & 7 & I & 53 \\
\hline 4 & \begin{tabular}{|c|}
$\begin{array}{c}\text { Khuvsgul } \\
\text { region }\end{array}$ \\
\end{tabular} & YI & 4 & $\mathrm{Y}$ & 5 & YII & 3 & YI & 4 & III & 7 & YI & 4 & YII & 3 & YII & 3 & Y & 5 & YIII & 38 \\
\hline 5 & Eastern & YII & 3 & IY & 6 & YIII & 2 & YII & 3 & YII & 3 & YII & 3 & $\mathrm{Y}$ & 5 & $\mathrm{Y}$ & 5 & YI & 4 & IX & 34 \\
\hline 6 & \begin{tabular}{|c|} 
Bulgan - \\
Selenge \\
region \\
\end{tabular} & IX & 1 & IX & 1 & IX & 1 & I & 9 & I & 9 & III & 7 & I & 9 & III & 7 & YIII & 2 & $\mathrm{Y}$ & 46 \\
\hline 7 & Gobi & II & 8 & III & 7 & III & 7 & IX & 1 & II & 8 & YIII & 2 & III & 7 & I & 9 & IX & 1 & III & 50 \\
\hline 8 & \begin{tabular}{|c|} 
High \\
mountain \\
region \\
\end{tabular} & YIII & 2 & YIII & 2 & I & 9 & Y & 5 & YIII & 2 & I & 9 & IX & 1 & YIIII & 2 & II & 8 & YII & 40 \\
\hline 9 & $\begin{array}{l}\text { Border } \\
\text { region }\end{array}$ & I & 9 & I & 9 & II & 8 & YIII & 2 & IX & 1 & IX & 1 & YIII & 2 & II & 8 & I & 9 & IY & 49 \\
\hline
\end{tabular}

This general ranking only relates to destinations based on the 9 satisfaction factors assessed according to the survey questionnaire (Figure 2). In other words, the travel regions of Mongolia were ranked based on the results of the survey and the tourist satisfaction survey.

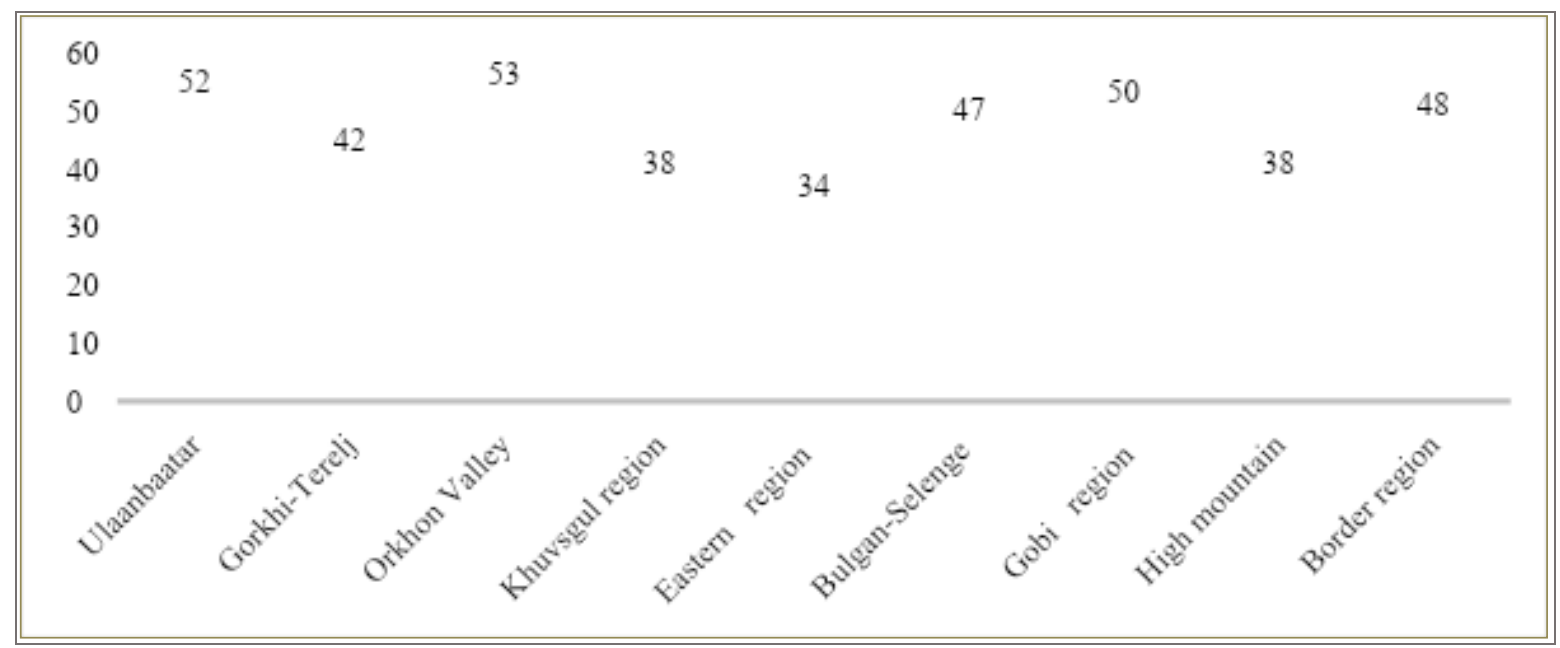

Fig. 2. General ranking assessment of destination (points)

Gray calculated the "destination ranking" using a correlation method, converted it to a numerical value, and determined the ranking of the 9 travel regions. This shows that Chinese tourists visit the Orkhon Valley, Ulaanbaatar, and Gobi regions in terms of competitiveness.

The region's high competitiveness varies on nine factors that affect the destination and it shows the difference in the study. The ranking of satisfaction factor indicators (Fig. 3) were considered for each destination. 


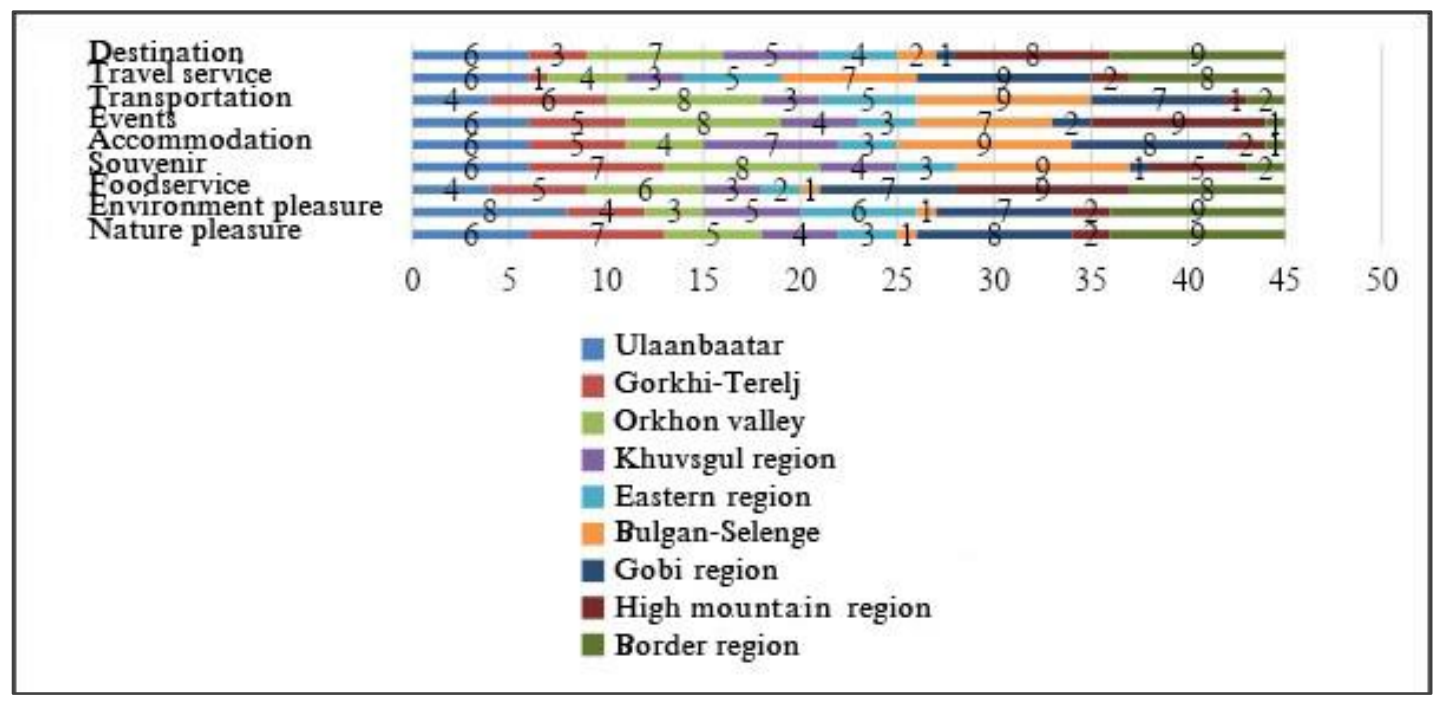

Fig. 3. Factors ranking of destination (point)

Conclusions. To determine the competitiveness of tourism regions is important for strengthening the region's strengths, improving its weaknesses, and developing sustainable development policies. Ulaanbaatar, the Orkhon Valley, the Gobi, and the border areas are the most competitive, as the weak regions include the Eastern region, the western or High Mountain region, and the Khuvsgul region. The weak regions are spatially remote, the exhibit distance is long, and roads and infrastructure are poorly developed, which makes them less competitive. Based on the satisfaction of about 170,000 Chinese tourists visiting Mongolia (MNET report, 2019), destination ranking was made by Gray correlation method and concluded as follows.

- Regardless of the region is close, short-term (5-7 days) and low-cost (about 1,000 yuan) trips are purchased, depending on income level and purpose of the trip;

- Tourists are interested in nature, historical and urban travel, and the number of tourists is not increasing well enough due to poor information access and visa issues.

Finally, this study can be the basis paper for the Government of Mongolia to steadily increase the number of Chinese tourists, to increase the number of products and services to key markets addressing infrastructure issues (Report of the Director of the Ministry of Nature, Environment and Tourism, 2019) and decision making.

\section{REFERENCES}

1. Avkhinsukh J., Sodnomvaanchig G., Amgalan A., (2009). Mongolian social economic geography. Ulaanbaatar. p. 132, p. 224-226.

2. National Center of Tourism. (2012). Basic research on Tourism. Ulaanbaatar

3. Development center of Tourism, Bank of Mongolia., (2019). The current situation of the tourism sector and decisive problems. Study report. Ulaanbaatar

4. Baasannamjil G., (2017). Theory of tourism marketing. Ulaanbaatar

5. Baatartsooj G., (2006). Stable tourism. Ulaanbaatar

6. Dash D., Mandakh N., Bayasgalan L. (2005). Recreation and tourism. Ulaanbaatar p.8-20, p65-66.

7. Khishigdalai U., (2016). Competitiveness rating of Mongolian tourist destinations. Thesis for a Ph.D. in Business Administration. Ulaanbaatar

8. Charles R. Goeldner, Translated by Li Tianyuan, (2014). Tourism / 12th edition/Renmin University Press, China

9. Shi Yanjun., (2015). Tourism. Commercial Press

10. Bao Jiang., (2012). Tourism geography. Higher education Press

11. Shi Yanjun., (2018). Tourism research methods. Chinese travel Press

12. Liu Sifeng., Guo Tianbang., Dang Yaoguo., (1999). Gray system theory and its application. scientific press

13. Zhang Hongmei., Yang Zhao., Lu Lin., (2016). Empirical approaches to tourism management research. Science Press

14. Jean Yuin., (2010). A study of the laws and dynamic mechanisms of temporal and spatial evolution in Beijing. dissertation work of Shaanxi Teacher's University 